\title{
The relationshop between physical exercise, clinical and cognitive characteristics and BDNF levels in patients with severe mental disorders
}

Monica Aas ${ }^{1-2 *}$, Srdjan Djurovic ${ }^{3-4}$, Torill Ueland ${ }^{1-5}$, Ragni H. Mørch ${ }^{1}$, Jannicke Fjæra Laskemoen $^{1}$, Elina J Reponen ${ }^{1}$, Annamaria Cattaneo ${ }^{5-6}$, Nils Eiel Steen ${ }^{1-2}$, Ingrid Agartz ${ }^{1-2,7-}$ ${ }^{8}$, Ingrid Melle ${ }^{1-2}$, Ole A. Andreassen ${ }^{1-2}$

${ }^{1}$ NORMENT, Institute of Clinical Medicine, University of Oslo, Norway;

${ }^{2}$ NORMENT, Division of Mental Health and Addiction, Oslo University Hospital, Oslo, Norway;

${ }^{3}$ Department of Medical Genetics, Oslo University Hospital, Oslo, Norway;

${ }^{4}$ NORMENT, KG Jebsen Centre for Psychosis Research, Department of Clinical Science, University of Bergen, Bergen, Norway

${ }^{5}$ Department of Psychology, University of Oslo, Norway

5 Biological psychiatry Unit, IRCCS Fatebenefratelli Brescia, Italy;

${ }^{6}$ Institute of Psychiatry, Kings College London, UK;

${ }^{7}$ Department of Psychiatric Research, Diakonhjemmet Hospital, Oslo, Norway, and

${ }^{8}$ Department of Clinical Neuroscience, Karolinska Institutet, Stockholm, Sweden

\section{*Corresponding Author:}

Monica Aas, $\mathrm{PhD}$

NORMENT, KG Jebsen Psychosis Research Centre, TOP study group

Division of Mental Health and Addiction, Institute of Clinical Medicine

Bygg 49, Ullevål sykehus,

PO Box 4956 Nydalen, 0424 Oslo, Norway

Email: monica.aas@medisin.uio.no 
Keywords: Schizophrenia, bipolar disorder, physical exercise, childhood trauma, cognitive function, mood symptoms.

\section{ABSTRACT}

Background: Human and animal studies suggest that physical exercise improves cognitive function and mood, potentially via an increase of Brain-derived-neurotrophic factor (BDNF). However, studies have been small and potentially underpowered. Here, we aimed to clarify the role of physical exercise on cognitive function and current mood in severe mental disorders in the most extensive sample to date. Secondly, we aimed to investigate the relationship between physical exercise and BDNF mRNA levels

Methods: Three hundred and six patients with a DSM-IV Schizophrenia (SZ) or Bipolar Disorder spectrum (BD) diagnosis were included. Clinical characteristics were assessed using the Structured Clinical Interview for DSM-IV. All patients underwent neuropsychological assessment. Physical exercise was measured as hours spent on any regular physical activity ( $\geq$ or $<90 \mathrm{~min}$ ) per week. BDNF mRNA was measured using standardized procedures.

Results: Patients with $\geq 90$ min of exercise per week had fewer depressive symptoms $(p<0.001$, Cohen's $d=0.48)$ and performed significantly better on working memory $(p<0.001$, $\mathrm{d}=0.44)$ and executive functioning $(\mathrm{p}<0.001, \mathrm{~d}=0.50)$ compared to the $<90 \mathrm{~min}$ group. Findings remained significant after adjusting for premorbid cognitive functioning, age, and sex. BDNF mRNA was positively associated with physical exercise $(\mathrm{p}=0.046)$ and cognitive functioning $(\mathrm{p}=0.037)$.

Limitations: As our study is a cross-sectional study, we cannot infer causality, only associations. 
Conclusions: Our findings of increased levels of mRNA BDNF associated with improved clinical characteristics and high physical exercise suggest an underlying mechanistic link.

Further studies of the mechanisms underlying the beneficial effects of physical exercise in severe mental illness are warranted. 


\section{INTRODUCTION}

Severe mental disorders, including schizophrenia spectrum disorders (SZ) and bipolar spectrum disorders (BD) are severe mental disorders characterised by psychosis and changes in mood often followed by cognitive dysfunction, including difficulties with problem solving, memory and executive functioning (Aas et al., 2014a, Bourne et al., 2013). At average people with SZ function at a cognitive level of approximately one standard deviation below that of healthy comparison groups (Aas et al., 2014a, Bozikas and Andreou, 2011, Lewandowski et al., 2011, Simonsen et al., 2011). Cognitive function also predicts current and later functional outcome, providing a rationale for attempts to find psychopharmacological or psychological interventions to ameliorate cognitive dysfunction in SZ (Green et al., 2004, Lystad et al., 2014, Tandberg et al., 2013). To date, cognitive deficits persist after successful treatment of psychotic symptoms (Rund et al., 2007, van Os and

Kapur, 2010). Most individuals with SZ are not working but depend on social benefits with an estimation of 55000 pounds per person per year (UK) (Mangalore and Knapp, 2007). Thus, investigations of new treatment regimens are of great importance, especially new alternative of low cost and easily assessable treatments.

In addition to the global cognitive impairment, specific domains present greater dysfunction, including episodic memory, working memory and executive function (Flashman and Green, 2004, Reichenberg et al., 2009). It is important to note that there are also patients with SZ with cognitive functioning in the normal or above-normal range (Allen et al., 2003;Goldstein, 1990;Heinrichs and Awad, 1993; Reichenberg et al., 2009;Silverstein and Zerwic, 1985).

However, also in the high cognitive function subgroup, the majority (64\%) still have abnormal scores on at least one cognitive domain (Vaskinn et al., 2014), with brain volume correlates (Vaskinn et al., 2015). Recent review papers show that cognitive impairment is also 
found in BD particularly in specific areas of working memory, executive functioning, attention, and processing speed (Bourne et al., 2013, Lewandowski et al., 2011, Simonsen et al., 2011).

Depression is a core symptom of $\mathrm{BD}$, and a diagnostic criteria. Depression is also commonly reported in patients with psychosis (Sonmez et al., 2013, Romm et al., 2010), with an increased risk of suicide during the early phases of psychotic illness (Nordentoft et al., 2011, Sim et al., 2004). Thus, low-cost treatments to improve depressive symptoms could have significant benefits in both $\mathrm{BD}$ and $\mathrm{SZ}$ populations. Depression is also related to cognitive dysfunction (ref), which may be seen in both disorders (ref). Further, mood episodes are also an independent predictior of functional impairments (ref)

Another major issue in modern psychiatry is the poor physical health and increased suicide rate in patients with $\mathrm{SZ}$ and $\mathrm{BD}$, which are causing a reduction in life expectancy by 10-15 years (Bitter et al., 2017, Firth et al., 2015, Osby et al., 2016). Recent studies indicate that physical exercise can benefit cognitive function, mood symptoms, and functional recovery, in addition to improving general physical health in severe mental disorder (Firth et al., 2015, Bitter et al., 2017 ). Thus, regular physical exercise in SZ and BD has the potential as a low cost and an easily assessable treatment option. Studies show that interventions of at least $\geq 90$ min of moderate to vigorous physical exercise, such as aerobic exercise, fast walking, cycling, or football playing have a positive effect on cognitive function (mostly studied is memory) and improved general mental, mood or physical health (Firth et al., 2015). Indeed, physical exercise is known to protect neurons from various brain insults, promote neurogenesis and potentially enhance cognitive function (Collins et al., 2009).

Brain-Derived Neurotrophic Factor (BDNF) is a Nerve Growth Factor protein essential for growth and differentiation of neurons during brain development as well as 
synaptic plasticity and maintenance of neurons in adult life. BDNF has been linked to cognitive functioning in animals; however, studies in humans are sparse (Piepmeier \& Etnier 2015). Patients with mental disorders including SZ have reduced BDNF levels compared to healthy controls (HC) in the brain (Durany et al., 2001), and in the blood (Buckley et al., 2011, Durany et al., 2001, Ikeda et al., 2008). Interestingly, several animal studies have found that physical exercise increases BDNF mRNA levels in the brain (Zoladz and Pilc, 2010). Hence, physical exercise could potentially improve cognitive function in severe mental illness by a BDNF pathway (Kim et al., 2015, Park et al., 2014, Archer et al., 2014). The knowledge about the role of physical exercise on cognitive functioning and symptom severity, as well as on BDNF mRNA levels in severe mental disorders is limited. Previous studies may have been hampered by small studies $(\mathrm{N}<100)$ reducing the ability to appropriately adjust for key factors, including premorbid functioning, age, sex or variation in BDNF levels based on differences in BDNF Val66Met genotype (Aas et al., 2014).

The aim of the present study was to gain more knowledge about the relationship between physical exercise and cognitive and clinical characterstics, and the association with mRNA BDNF levels. We investigated the following hypotheses:1) At least 90 min of physical exercise per week will be associated with better cognitive function and less severe mood symptoms (focus on depressive symptoms). 2) Higher blood BDNF mRNA levels will be associated with better cognitive functioning and more hours exercising per week.

\section{METHODS}

\section{Participants}

The participants were recruited consecutively from psychiatric units (outpatient and inpatient) of 4 major hospitals in Oslo, as part of the larger NORMENT, Thematically 
Organized Psychosis (TOP) Research study. A total of three hundred and six participants (schizophrenia [ $n=177]$ or bipolar disorders $[n=129]$ ) were recruited to the study. Two hundred and nineteen (71.6\%) of the participants were taking at least one type of antipsychotic medication; $104(34.0 \%)$ used antidepressants. The mean age of the patients was $29.9 \pm 10.4$, and $51 \%$ were males. Mean age at first received treatment for psychosis was 23.7 \pm 9.2 years. Physical exercise was defined as hours spent on any physical activity per week. Exclusion criteria for all groups were: hospitalized head injury, neurological disorder, unstable or uncontrolled medical condition that interferes with brain function, IQ below 70 and age outside the range of 18-65 years. The Regional Committee for Medical Research Ethics and the Norwegian Data Inspectorate approved the study. All participants gave written informed consent.

\section{Clinical Assessment}

Trained physicians, psychiatrists, and clinical psychologists carried out the clinical assessment. The diagnosis was based on the Structured Clinical Interview for DSM-IV Axis I disorders (SCID-I). Diagnostic reliability was found satisfactory (Ringen et al., 2008) with an overall agreement for DSM-IV diagnostic categories of $82 \%$ and the overall $\kappa 0.77$ (95\% CI: 0.60-0.94). Medication at time of testing was determined through clinical interview and medical charts. Depressive symptomatology was measured using the Inventory of Depressive Symptoms (IDS-C) and the Calgary Depression Scale for Schizophrenia (CDSS). Symptom severity and function were rated separately using a split version of the Global Assessment of Functioning Scale (GAF, Pedersen et al., 2007)

\section{Neurocognitive Assessment}


Included in this study are measures previously found sensitive to dysfunction in SZ and BD (Aas et al., 2014a; Bozikas and Andreou, 2011; Lewandowski et al., 2011). The following domains were assessed: 1) Memory, 2) Working memory, 3) Executive function and 4) IQ (verbal and performance subtests). To examine performance by domain, raw scores within each domain were standardized into z-scores (for further details, see Aas et al., 2014).

The neurocognitive assessments were carried out by psychologists trained in standardized neuropsychological testing. A 3-hour test battery was administered in a fixed order with two breaks with refreshments. The neuropsychological battery was composed as follows: Working memory was measured using the Letter-Number Sequencing, Digit Span forwards, and Digit Span backwards (Wechsler, 2003); Executive function was measured using the Verbal Fluency Test (Delis-Kaplan Executive Function Scale [D-KEFS]) (Delis 2004) including phonetic fluency and semantic fluency; Memory was measured using Logical Memory test at immediate and delayed (30 minutes) time points (Wechsler, 2007). General intellectual abilities: Performance abilities (perception and visuospatial abilities) were measured using the Block Design task and the Matrix Reasoning from the WASI (Wechsler, 2007); Verbal abilities were measured by Similarities and the Vocabulary from the WASI (Wechsler, 2007). The National Adult Reading Test (NART), was used to assess premorbid cognitive functioning (Vaskinn, A. \& Sundet, K. 2001).

\section{Genotyping}

DNA was extracted from blood and genotyped using the Affymetrix Human SNP Array 6.0 (Affymetrix Inc, Santa Clara, CA, USA), as previously reported (Djurovic et al., 2010). All chips were subjected to the Birdseed-v2 algorithm developed by Affymetrix Inc. and Broad Inst (Kom et al., 2008) and implemented in the software respiratory Affymetrix Power Tools (APT v1.10). 


\section{BDNF mRNA expression Analyses}

Blood samples for gene expression analysis of BDNF were collected using Tempus Blood RNA Tubes (Life Technologies Corporation, Carlsbad, CA, USA), and stored at $-80^{\circ} \mathrm{C}$ until analysis. Total RNA was extracted either automated with the ABI PRISM 6100 Nucleic Acid PrepStation (Life Technologies Corporation, Carlsbad, CA, USA) and the Tempus 12port RNA Isolation Kit or manually with the Tempus Spin RNA Isolation Kit (Life Technologies Corporation, Carlsbad, CA, USA) according to the manufacturer's protocol. The analyses have been published elsewhere (Aas et al., 2014b).

\section{Statistics}

Data were analyzed using the IBM SPSS software, Version 25. T-Tests were performed to investigate exercise $\geq$ or $<$ than 90 min per week and clinical characteristics. Ninty min of exercise per week was both the median of time reported in our sample, as well as the time recommended to have an effect on cognition and physical health in the meta-analysis by Firth et al., (2015). In addition to $\geq$ or $<$ than 90 min per week, physical exercise was also analyzed as a continuous variable using multiple regression. As age, gender and diagnosis (SZ or BD) may influence the cognitive and clinical features investigated in this study, these variables were added as confounders in the model. To control for the possibility of patients with better cognitive function exercising more than patients with lower cognitive function, we controlled for premorbid IQ (NART). Antidepressants was initially included as a confounder in the analyses due to previous findings of an antidepressant increase in plasma BDNF levels (Zhou et al., 2017) but antidepressant was eventually taken out of from the final model as it did not improve the model. Effect sizes were computed based on comparing the two groups ( $\geq$ or $<$ than 90 min of exercise per week) using Cohen's d (Cohen, 1977). According to Rosenthal 
and Rosnow (Rosenthal and Rosnow, 1984), effect sizes were considered small for values between 0.20 and 0.50 , moderate for values between 0.50 and 0.80 , and large for values higher than 0.80 .

For the BDNF mRNA analysis, BDNF Val66Met genotype was added as a confounder as we have previously reported that different variants of the BDNF Val66Met are related to different BDNF mRNA expression (Aas et al., 2014b). As there is no recommended minimum time of physical exercise to influence BDNF levels, physical exercise was also investigated as a continuous variable. The threshold for statistical significance was set at $\mathrm{p}<0.05$ with Post hoc Bonferroni corrections.

\section{RESULTS}

Demographics and clinical characteristics of the sample divided into $\geq$ or $<$ than 90 min of exercise per week

No differences between groups were observed for age, gender, or premorbid cognitive function. The group who exercised $\geq 90$ min per week were more likely to be BDNF Val66Met-Val/Val carriers, and had a better global functioning (GAF scores; $\mathrm{p}<0.001$, Cohen's d=0.33). The group who exercised $\geq 90$ min per week also had higher scores on working memory ( $p<0.001$, Cohen's $=0.44)$, executive functioning $(p<0.001$, Cohen's $\mathrm{d}=0.50)$, verbal memory $(\mathrm{p}=0.04$, Cohen's $\mathrm{d}=0.25)$, and general intellectual abililties $(\mathrm{p}=0.02$, Cohen's d=0.27); see Table 1. The same group had significantly less depressive symptomatology measured by the IDS-C and the CDSS ( $p<0.001$, Cohen's $=0.48$ and $p=0.01$, 
Cohen's $=0.31$, respectively). Higher scores on working memory, executive functioning, and verbal memory correlated with better functioning (GAF; $\beta=0.23, \mathrm{p}<0.001, \beta=0.25, \mathrm{p}<0.001$, $\beta=0.23$, and $p<0.001$, respectively), but not depressive symptoms (CDSS or IDS-C; $p>0.1$ ).

Patients with BD had higher scores on BDNF mRNA levels compared to SZ (mean $\pm \mathrm{SD}=1.00 \pm 0.39$, compared to $1.13 \pm 0.45 ; \mathrm{t}=-2.84, \mathrm{p}=0.005)$. Met carriers of the BDNF Val66Met also had significantly lower BDNF mRNA levels compared to Val/Val carriers (mean $\pm \mathrm{SD}=0.92 \pm 0.37$ compared to $1.07 \pm 0.39 ; \mathrm{t}=3.56, \mathrm{p}<0.001$, see Table 1).

-Insert Table 1 here-

\section{Physical exercise is associated with better cognitive functioning}

A multiple regression analysis was performed to investigate the association between physical exercise (as a continuous variable) on cognitive function adjusting for age, gender and diagnosis (SZ or BD, see Table 2). There was a positive association between physical exercise and working memory $(\beta=0.16, p=0.006)$, and executive functioning $(\beta=0.15$, $\mathrm{p}=0.006)$, with no significant findings for verbal memory $(\beta=0.06, \mathrm{p}=0.53)$.

\section{-Insert Table 2 here-}

When premorbid cognitive function (NART) was added into the model, a significant link between physical exercise (measured as a continuous variable) and better scores for working memory and executive functioning was still observed $(\beta=0.12, p=0.01$, and $\beta=0.10$, $\mathrm{p}=0.03$, respectively, see Supplementary Material Table S2). Finally, we did not observe any interaction effects between diagnoses (SZ vs. BD) and exercise (see Supplementary Material, Figure S1). 


\section{BDNF mRNA levels, cognitive function, and mood symptoms}

A significant association was observed between BDNF mRNA levels and general intellectual abilities measured by WASI $(\beta=0.12, \mathrm{p}=0.037)$, in the direction of higher BDNF mRNA in the patients who had better cognitive performance. No association was observed for IDS-C and BDNF mRNA ( $\mathrm{p}>0.1)$.

\section{BDNF mRNA and physical exercise}

No association was observed between physical exercise measured as a dichotomous variable ( $\geq$ more or $<$ than 90 min per week), and BDNF mRNA levels $(\mathrm{p}>0.1)$. Investigating hours spent exercising per week as a continuous variable and BDNF mRNA levels showed a significant association between physical exercise and BDNF mRNA levels $(ß=0.11, \mathrm{p}=0.046)$. A significant positive relationship between hours spent on physical exercise on BDNF mRNA levels was also observed after correcting for possible confounders (diagnosis, and BDNF Val66Met genotype $(\Omega=0.15, \mathrm{p}=0.026)$ ). However, considerable variation in the data was observed (see Supplementary Material Table S3).

\section{DISCUSSION}

Our study gives new knowledge on the role of physical exercise in SZ and BD by showing significant association to better cognitive functioning, fewer symptoms and higher BDNF mRNA levels. Our study demonstrates a positive relationship between physical exercise and better cognitive functioning in patients with $\mathrm{SZ}$ or $\mathrm{BD}$, specifically for working memory tasks. This finding was not explained by differences in diagnosis (SZ or BD) or 
cognitive functioning before illness onset measured by the NART. Physical exercise of $\geq 90$ min per week was also associated with less severe depressive symptoms, and higher GAF scores supporting a potential multi-target effect of physical exercise in severe mental disorders.

Our large study (N=306) confirms the previous findings by Firth et al., (2015), suggesting that at least 90 minutes of exercise per week is associated with better cognition and less mood symptoms. Previous studies have shown a positive association between exercise and BDNF levels in humans (Aas et al., 2014b), as well as in animals (Kim et al., 2015; Park et al., 2014). In fact, our findings of better cognitive function in the group with regular physical exercise could be related to an increase in BDNF mRNA levels in the brain (Zoladz and Pilc, 2010). Our finding supports an association between regular physical exercise and increased BDNF levels with a moderate effect on cognitive function. However, we only found an association between BDNF mRNA levels and physical exercise analyzed as a continuous variable and not as a dichotomous variable. In fact, it was the participants reporting the highest percentile of time exercising who had the highest BDNF mRNA levels (five hours or more of exercising per week, see Supplementary Material Figure S2). Thus, 90 min of exercise may be at the lower range for having a change in BDNF levels in peripheral blood.

That physical exercise promotes resilience and reduces stress levels is well known (Deuster and Silverman, 2013). About half of patients with SZ or BD report a history of childhood trauma, compared to around $10 \%$ of the general population (Church, 2017). Large meta-analyses confirm childhood trauma to three-fold the risk of developing a psychotic illness (Varese et al., 2012). Patients with SZ or BD who report a history of childhood trauma also have lower BDNF levels measured in peripheral blood, compared to similar patient groups who do not report trauma (Aas et al., 2014b, Mondelli et al., 2011). It has been proposed that a history of childhood trauma sensitize the biological stress system, increases 
the subjective stress level, potentially making the individual more vulnerable to develop psychopathology (Aas et al., 2016, Pruessner et al., 2016). We postulate that physical exercise, in conjunction with regular treatment may reduce the physiological and subjective stress response, and potentially reduce the adverse long-term effects of childhood trauma in SZ and BD.

Physical exercise in SZ and BD is a low cost and an easily administered treatment. In our study and other studies, regular physical exercise is associated with better cognitive functioning as well as less severe affective symptomatology, such as depressive symptoms (Firth et al., 2015), supporting exercise as a potential multi-target treatment in SZ and BD.

Some limitations of the current study must be mentioned. First, we used the short-form WASI instead of the full-scale WAIS. Numerous short forms of the WAIS have been developed to reduce administration time while generating a reliable estimate of full-scale IQ (FSIQ) (Cyr, 1984, Silverstein and Zerwic, 1985). Individuals with psychosis tend to show more variations on subtests scores compared to healthy controls (Flashman \& Green, 2004), which indicate that using subtests of the battery may decrease the accuracy of the results. On the other hand, patients with psychosis have a limited attention span. Therefore short versions of the WAIS, which are less time consuming, have been found to be beneficial (Allen et al., 1997). Secondly, peripheral BDNF levels were used as a surrogate biomarker of CNS physiology (BDNF was not measured directly in the brain). Reassuringly it has been found plasma BDNF levels reflect brain-tissue BDNF levels (Klein et al., 2011). However, it is still only an estimate of activity in the brain, and not a measure directly from the CNS in itself. Although we found a significant positive correlation between BDNF mRNA levels and physical exercise measured as a continuum variable, large variation in the data was present. Thus our findings should be interpreted with caution until further replications. Finally, we asked participants how many hours of exercise they normally performed each week, without 
controlling for specific type of exercise, or using a randomized follow-up study. Reassuringly, the review paper by Firth et al., (2015) concluded that any moderate to vigorous exercise including jogging, cycling, sports or resistance training, independent of type, had a positive effect on mood symptom reduction and cognitive functioning, supporting our broad nonspecific approach to exercise. As our study is a cross-sectional study, we cannot infer causality between physical exercise and better mood and cognition, which can only be inferred using longitudinal studies. However, when we corrected for premorbid IQ (NART), those who reported exercising at least 90 minutes per week had better working memory and executive performance, adjusting for the fact that individuals with higher cognitive functioning may exercise more in the first place. However, we can not rule out that those who exercised less than 90 minutes per had a larger reduction in cognitive functioning after illness onset, or if physical exercise could protect from a fall in cognition from premorbid to illness onset. Moreover, no difference in years of education or premorbid functioning (NART) was observed between the groups ( $<90 \mathrm{~min} / \geq 90 \mathrm{~min}$ of physical exercise per week).

To conclude, our results of increased levels of mRNA BDNF associated with improved clinical characteristics and high physical exercise suggest an underlying mechanistic link. Further studies of the mechanisms underlying the beneficial effects of physical exercise in severe mental illness are warranted. Physical exercise is a low cost treatment option which can be easily implemented.

\section{FINANCIAL DISCLOSURE}

This study was funded by grants from the University of Oslo, South-Eastern Norway Health Authority (\#2013088, \#2017060), the Research Council of Norway (\#223273, 
\#248778, \#248980), and the KG Jebsen Foundation. This study was also funded by the

NARSAD Young Investigator Award (\#22388), and the Scandinavian College of

Neuropsychopharmacology (SCNP) Young Scientist grant to Monica Aas.

\section{ACKNOWLEDGEMENTS}

We thank the patients who took part in the study as well as NORMENT, which contributed

to the data collection. Specific thanks to T B for excellent help in organizing the database.

\section{CONFLICT OF INTEREST}

None to declare.

\section{References}

Aas, M., Dazzan, P., Mondelli, V., Melle, I., Murray, R. M. \& Pariante, C. M. (2014a). A Systematic Review of Cognitive Function in First-Episode Psychosis, Including a Discussion on Childhood Trauma, Stress, and Inflammation. Front Psychiatry 4, 182.

Aas, M., Haukvik, U. K., Djurovic, S., Tesli, M., Athanasiu, L., Bjella, T., Hansson, L., Cattaneo, A., Agartz, I., Andreassen, O. A. \& Melle, I. (2014b). Interplay between childhood trauma and BDNF val66met variants on blood BDNF mRNA levels and on hippocampus subfields volumes in schizophrenia spectrum and bipolar disorders. J. Psychiatr. Res.

Aas, M., Henry, C., Andreassen, O. A., Bellivier, F., Melle, I. \& Etain, B. (2016). The role of childhood trauma in bipolar disorders. Int J Bipolar Disord 4, 2.

Aas, M., Steen, N. E., Agartz, I., Aminoff, S. R., Lorentzen, S., Sundet, K., Andreassen, O. A. $\&$ Melle, I. (2012). Is cognitive impairment following early life stress in severe mental disorders based on specific or general cognitive functioning? Psychiatry Res 198, 495-500.

Allen, D. N., Huegel, S. G., Gurklis, J. A., Jr., Kelley, M. E., Barry, E. J. \& van Kammen, D. P. (1997). Utility of WAIS-R short forms in schizophrenia. Schizophr. Res 26, 163-172.

Archer, T., Josefsson, T. \& Lindwall, M. (2014). Effects of physical exercise on depressive symptoms and biomarkers in depression. CNS Neurol Disord Drug Targets 13, 1640-53. 
Athanasiu L, Mattingsdal M, Kähler AK, Brown A, Gustafsson O, Agartz I, Giegling I, Muglia P, Cichon S, Rietschel M, Pietiläinen OP, Peltonen L, Bramon E, Collier D, Clair DS, Sigurdsson E, Petursson H, Rujescu D, Melle I, Steen VM, Djurovic S, Andreassen OA. Gene variants associated with schizophrenia in a Norwegian genome-wide study are replicated in a large European cohort. J Psychiatr Res. 2010 Sep;44(12):748-53.

Bitter, I., Czobor, P., Borsi, A., Feher, L., Nagy, B. Z., Bacskai, M., Rakonczai, P., Hegyi, R., Nemeth, T., Varga, P., Gimesi-Orszagh, J., Fadgyas-Freyler, P., Sermon, J. \& Takacs, P. (2017). Mortality and the relationship of somatic comorbidities to mortality in schizophrenia A nationwide matched-cohort study. Eur Psychiatry 45, 97-103.

Bourne, C., Aydemir, O., Balanza-Martinez, V., Bora, E., Brissos, S., Cavanagh, J. T., Clark, L., Cubukcuoglu, Z., Dias, V. V., Dittmann, S., Ferrier, I. N., Fleck, D. E., Frangou, S., Gallagher, P., Jones, L., Kieseppa, T., Martinez-Aran, A., Melle, I., Moore, P. B., Mur, M., Pfennig, A., Raust, A., Senturk, V., Simonsen, C., Smith, D. J., Bio, D. S., Soeiro-de-Souza, M. G., Stoddart, S. D., Sundet, K., Szoke, A., Thompson, J. M., Torrent, C., Zalla, T., Craddock, N., Andreassen, O. A., Leboyer, M., Vieta, E., Bauer, M., Worhunsky, P. D., Tzagarakis, C., Rogers, R. D., Geddes, J. R. \& Goodwin, G. M. (2013). Neuropsychological testing of cognitive impairment in euthymic bipolar disorder: an individual patient data metaanalysis. Acta Psychiatr Scand 128, 149-62.

Bozikas, V. P. \& Andreou, C. (2011). Longitudinal studies of cognition in first episode psychosis: a systematic review of the literature. Aust. N. Z. J Psychiatry 45, 93-108.

Brickman, A. M., Buchsbaum, M. S., Bloom, R., Bokhoven, P., Paul-Odouard, R., Haznedar, M. M., Dahlman, K. L., Hazlett, E. A., Aronowitz, J., Heath, D. \& Shihabuddin, L. (2004).

Neuropsychological functioning in first-break, never-medicated adolescents with psychosis. J. Nerv. Ment. Dis 192, 615-622.

Buckley, P. F., Pillai, A. \& Howell, K. R. (2011). Brain-derived neurotrophic factor: findings in schizophrenia. Curr. Opin. Psychiatry 24, 122-127.

Church, C. A., OA; Lorentzen, S., Melle, I., Aas, M (2017). Childhood trauma and minimization/denial in people with and without a severe mental disorder Frontiers in Psychiatry.

Collins, A., Hill, L. E., Chandramohan, Y., Whitcomb, D., Droste, S. K. \& Reul, J. M. (2009). Exercise improves cognitive responses to psychological stress through enhancement of epigenetic mechanisms and gene expression in the dentate gyrus. PLoS. One 4, e4330.

Cyr, J. (1984). Use of appropriate formulas for selecting WAIS-R short forms. (ed. B. H Brooker), pp. 903-905: J.Consult. Clin. Psychol.

Deuster, P. A. \& Silverman, M. N. (2013). Physical fitness: a pathway to health and resilience. US Army Med Dep J, 24-35.

Djurovic S, Gustafsson O, Mattingsdal M, Athanasiu L, Bjella T, Tesli M, Agartz I, Lorentzen S, Melle I, Morken G, Andreassen OA.A Genome-wide association study of bipolar disorder in Norwegian individuals, followed by replication in Icelandic sample.J Affect Disord. 2010 Oct;126(1-2):312-6. 
Durany, N., Michel, T., Zochling, R., Boissl, K. W., Cruz-Sanchez, F. F., Riederer, P. \& Thome, J. (2001). Brain-derived neurotrophic factor and neurotrophin 3 in schizophrenic psychoses. Schizophr. Res 52, 79-86.

Fernandes, B. S., Steiner, J., Berk, M., Molendijk, M. L., Gonzalez-Pinto, A., Turck, C. W., Nardin, P. \& Goncalves, C. A. (2014). Peripheral brain-derived neurotrophic factor in schizophrenia and the role of antipsychotics: meta-analysis and implications. Mol. Psychiatry.

Firth, J., Cotter, J., Elliott, R., French, P. \& Yung, A. R. (2015). A systematic review and meta-analysis of exercise interventions in schizophrenia patients. Psychol. Med, 1-19.

Flashman, L. A. \& Green, M. F. (2004). Review of cognition and brain structure in schizophrenia: profiles, longitudinal course, and effects of treatment. Psychiatr. Clin. North Am 27, 1-18, vii.

Green, M. F., Kern, R. S. \& Heaton, R. K. (2004). Longitudinal studies of cognition and functional outcome in schizophrenia: implications for MATRICS. Schizophr. Res 72, 41-51.

Ikeda, Y., Yahata, N., Ito, I., Nagano, M., Toyota, T., Yoshikawa, T., Okubo, Y. \& Suzuki, H. (2008). Low serum levels of brain-derived neurotrophic factor and epidermal growth factor in patients with chronic schizophrenia. Schizophr. Res 101, 58-66.

Kim, Y. M., Ji, E. S., Kim, S. H., Kim, T. W., Ko, I. G., Jin, J. J., Kim, C. J., Kim, T. W. \& Kim, D. H. (2015). Treadmill exercise improves short-term memory by enhancing hippocampal cell proliferation in quinolinic acid-induced Huntington's disease rats. J. Exerc. Rehabil 11, 5-11.

Klein, A. B., Williamson, R., Santini, M. A., Clemmensen, C., Ettrup, A., Rios, M., Knudsen, G. M. \& Aznar, S. (2011). Blood BDNF concentrations reflect brain-tissue BDNF levels across species. Int. J. Neuropsychopharmacol 14, 347-353.

Lewandowski, K. E., Cohen, B. M. \& Ongur, D. (2011). Evolution of neuropsychological dysfunction during the course of schizophrenia and bipolar disorder. Psychol. Med 41, 225241.

Lystad, J. U., Falkum, E., Mohn, C., Haaland, V. O., Bull, H., Evensen, S., Rund, B. R. \& Ueland, T. (2014). The MATRICS Consensus Cognitive Battery (MCCB): performance and functional correlates. Psychiatry Res 220, 1094-1101.

Mangalore, R. \& Knapp, M. (2007). Cost of schizophrenia in England. J. Ment. Health Policy Econ 10, 23-41.

Mondelli, V., Cattaneo, A., Belvederi, M. M., Di, F. M., Handley, R., Hepgul, N., Miorelli, A., Navari, S., Papadopoulos, A. S., Aitchison, K. J., Morgan, C., Murray, R. M., Dazzan, P. $\&$ Pariante, C. M. (2011). Stress and inflammation reduce brain-derived neurotrophic factor expression in first-episode psychosis: a pathway to smaller hippocampal volume. J Clin Psychiatry 72, 1677-1684.

Nordentoft, M., Mortensen, P. B. \& Pedersen, C. B. (2011). Absolute risk of suicide after first hospital contact in mental disorder. Arch. Gen. Psychiatry 68, 1058-1064.

Osby, U., Westman, J., Hallgren, J. \& Gissler, M. (2016). Mortality trends in cardiovascular causes in schizophrenia, bipolar and unipolar mood disorder in Sweden 1987-2010. Eur J Public Health 26, 867-871. 
Park, J. K., Lee, S. J. \& Kim, T. W. (2014). Treadmill exercise enhances NMDA receptor expression in schizophrenia mice. J. Exerc. Rehabil 10, 15-21.

Pedersen, G., Hagtvet, K. A. \& Karterud, S. (2007). Generalizability studies of the Global Assessment of Functioning-Split version. Compr. Psychiatry 48, 88-94.

Piepmeier, A. T., Etnier, J.L. (2015). Brain-derived neurotrophic factor (BDNF) as a potential mechanism of the effects of acute exercise on cognitive performance. Journal of Sport and Health Science 4, 9.

Pruessner, M., Cullen, A. E., Aas, M. \& Walker, E. F. (2016). The neural diathesis-stress model of schizophrenia revisited: An update on recent findings considering illness stage and neurobiological and methodological complexities. Neurosci Biobehav Rev.

Reichenberg, A., Harvey, P. D., Bowie, C. R., Mojtabai, R., Rabinowitz, J., Heaton, R. K. \& Bromet, E. (2009). Neuropsychological function and dysfunction in schizophrenia and psychotic affective disorders. Schizophr. Bull 35, 1022-1029.

Ringen, P. A., Lagerberg, T. V., Birkenaes, A. B., Engn, J., Faerden, A., Jonsdottir, H., Nesvag, R., Friis, S., Opjordsmoen, S., Larsen, F., Melle, I. \& Andreassen, O. A. (2008). Differences in prevalence and patterns of substance use in schizophrenia and bipolar disorder. Psychol. Med 38, 1241-1249.

Romm, K. L., Rossberg, J. I., Berg, A. O., Barrett, E. A., Faerden, A., Agartz, I., Andreassen, O. A. \& Melle, I. (2010). Depression and depressive symptoms in first episode psychosis. J Nerv. Ment. Dis 198, 67-71.

Rund, B. R., Melle, I., Friis, S., Johannessen, J. O., Larsen, T. K., Midboe, L. J., Opjordsmoen, S., Simonsen, E., Vaglum, P. \& McGlashan, T. (2007). The course of neurocognitive functioning in first-episode psychosis and its relation to premorbid adjustment, duration of untreated psychosis, and relapse. Schizophr. Res 91, 132-140.

Silverstein, M. L. \& Zerwic, M. J. (1985). Clinical psychopathologic symptoms in neuropsychologically impaired and intact schizophrenics. J. Consult Clin. Psychol 53, $267-$ 268.

Sim, K., Mahendran, R., Siris, S. G., Heckers, S. \& Chong, S. A. (2004). Subjective quality of life in first episode schizophrenia spectrum disorders with comorbid depression. Psychiatry Res 129, 141-147.

Simonsen, C., Sundet, K., Vaskinn, A., Birkenaes, A. B., Engh, J. A., Faerden, A., Jonsdottir, H., Ringen, P. A., Opjordsmoen, S., Melle, I., Friis, S. \& Andreassen, O. A. (2011).

Neurocognitive dysfunction in bipolar and schizophrenia spectrum disorders depends on history of psychosis rather than diagnostic group. Schizophr. Bull 37, 73-83.

Sonmez, N., Romm, K. L., Andreasssen, O. A., Melle, I. \& Rossberg, J. I. (2013). Depressive symptoms in first episode psychosis: a one-year follow-up study. BMC. Psychiatry 13, 106. 
Tandberg, M., Sundet, K., Andreassen, O. A., Melle, I. \& Ueland, T. (2013). Occupational functioning, symptoms and neurocognition in patients with psychotic disorders: investigating subgroups based on social security status. Soc. Psychiatry Psychiatr. Epidemiol 48, 863-874.

van Os, J. \& Kapur, S. (2010). [Psychosis: from diagnosis to syndrome]. Ned. Tijdschr. Geneeskd 154, A1874.

Varese, F., Smeets, F., Drukker, M., Lieverse, R., Lataster, T., Viechtbauer, W., Read, J., van, O. J. \& Bentall, R. P. (2012). Childhood adversities increase the risk of psychosis: a metaanalysis of patient-control, prospective- and cross-sectional cohort studies. Schizophr. Bull $38,661-671$.

Vaskinn, A., Hartberg, C. B., Sundet, K., Westlye, L. T., Andreassen, O. A., Melle, I. \& Agartz, I. (2015). Brain structure characteristics in intellectually superior schizophrenia. Psychiatry Res 232, 123-129.

Vaskinn, A. \& Sundet, K. (2001) Estimering av premorbid IQ: en norsk versjon av National Adult Reading Test. Tidsskrift for Norsk Psykologforening, 38, 1133-1140.

Vaskinn, A., Ueland, T., Melle, I., Agartz, I., Andreassen, O. A. \& Sundet, K. (2014). Neurocognitive Decrements are Present in Intellectually Superior Schizophrenia. Front Psychiatry 5, 45.

Wechsler, D. (2007). Wechsler Appreviated Scale of Intelligence (WASI).Norwegian manual supplement. Pearson Assessment.: Stockholm.

Wechsler D. Wechsler Adult Intelligence Scale: WAIS-III.Stockholm, Sweden: Pearson Assessment; 2003.

Zanelli, J., Reichenberg, A., Morgan, K., Fearon, P., Kravariti, E., Dazzan, P., Morgan, C., Zanelli, C., Demjaha, A., Jones, P. B., Doody, G. A., Kapur, S. \& Murray, R. M. (2010). Specific and generalized neuropsychological deficits: a comparison of patients with various first-episode psychosis presentations. Am. J. Psychiatry 167, 78-85.

Zhou, C., Zhong, J., Zou, B., Fang, L., Chen, J., Deng, X., Zhang, L., Zhao, X., Qu, Z., Lei, Y. \& Lei, T. (2017). Meta-analyses of comparative efficacy of antidepressant medications on peripheral BDNF concentration in patients with depression. PLoS One 12, 12(2): e0172270.

Zoladz, J. A. \& Pilc, A. (2010). The effect of physical activity on the brain derived neurotrophic factor: from animal to human studies. J Physiol Pharmacol 61, 533-41. 